\title{
LOW-BACK PAIN DISORDERS AS OCCUPATIONAL DISEASES IN THE CZECH REPUBLIC AND 22 EUROPEAN COUNTRIES: COMPARISON OF NATIONAL SYSTEMS, RELATED DIAGNOSES AND EVALUATION CRITERIA
}

\author{
Andrea Laštovková1, Marie Nakládalová2, Zdenka Fenclová1, ${ }^{3}$, Pavel Urban ${ }^{1,3}$, Petr Gad'ourek, Tomáš Lebeda ${ }^{3}$, \\ Edvard Ehler ${ }^{5}$, Petr Ridzoňn, Jana Hlávková3, Alena Boriková2, P. Paul F. M. Kuijer ${ }^{6}$, Igor Bátora ${ }^{7}$, Stefan M. \\ Scholz-Odermatt ${ }^{8}$, Horatiu Moldovan ${ }^{9}$, Lode Godderis ${ }^{10,11}$, Ola Leijon ${ }^{12}$, Giuseppe Campo ${ }^{13}$, Manuela \\ Vaněčková ${ }^{14}$, Vincent Bonneterre ${ }^{15}$, Elisaveta Jasna Stikova ${ }^{16}$, Daniela Pelclová ${ }^{1}$ \\ 'Department of Occupational Medicine, First Medical Faculty, Charles University and General University Hospital, Prague, Czech Republic \\ ${ }^{2}$ Department of Occupational Medicine, Faculty of Medicine and Dentistry, Palacký University in Olomouc and University Hospital, Olomouc, \\ Czech Republic \\ ${ }^{3}$ National Institute of Public Health, Prague, Czech Republic \\ ${ }^{4}$ GETA Centre, v.v.i., Prague, Czech Republic \\ ${ }^{5}$ Department of Neurology, Regional Hospital in Pardubice, Pardubice, Czech Republic \\ ${ }^{6}$ Netherlands Centre for Occupational Diseases, Coronel Institute of Occupational Health, Academic Medical Centre, University of Amsterdam, \\ Netherlands \\ ${ }^{7}$ Department of Occupational Medicine and Toxicology, Faculty of Medicine, Comenius University, Bratislava, Slovak Republic \\ ${ }^{8}$ Department of Statistics, Swiss Accident Insurance Trust (Suva), Lucerne, Switzerland \\ ${ }^{9}$ Occupational Medicine Department, University of Medicine and Pharmacy of Targu-Mures, Targu-Mures, Romania \\ ${ }^{10} \mathrm{Centre}$ for Environment and Health, KU Leuven, Leuven, Belgium \\ ${ }^{11}$ IDEWE External Service for Prevention and Protection at Work, Heverlee, Belgium \\ ${ }^{12}$ Swedish Social Insurance Inspectorate, and Institute of Environmental Medicine, Unit of Occupational Medicine, Karolinska Institute, Stockholm, \\ Sweden \\ ${ }^{13}$ Department of Medicine, Epidemiology and Occupational Hygiene, INAIL, Rome, Italy \\ ${ }^{14}$ Department of Radiodiagnostics, First Faculty of Medicine, Charles University in Prague and General University Hospital, Prague, Czech Republic \\ ${ }^{15}$ Occupational and Environmental Diseases Centre, Grenoble Teaching Hospital, Grenoble, France \\ ${ }^{16}$ Public Health Institut RM, UKIM, Medical Faculty, Skopje, Macedonia
}

\section{SUMMARY}

Aim: Low-back pain diseases (LBPD) belong to the most frequent diagnoses determined by general practitioners, and constitute one of the most common reasons for sick leave and permanent disability pension in the Czech Republic and other European countries. Epidemiological studies have shown a statistically significant association between LBPD and certain types of occupational burden. However, in the Czech Republic, LBPD caused by overload and/or whole-body vibrations have not yet been included in the list of occupational diseases. The aim of this study was to collect and compare the systems, criteria and diagnoses used to recognize LBPD as occupational diseases in other European countries.

Methods: A questionnaire focused on LBPD was distributed and answered by specialists in occupational diseases in European countries. It included items concerning LBPD in the national list of occupational diseases, and work-related and diagnostic criteria that need to be fulfilled for recognizing LBPD as occupational diseases and possible awarding compensations to the patients.

Results: In 13 countries out of the 23 countries studied, LBPD caused by overload can be recognized as occupational, providing that the diagnosis is sufficiently proven and exposure criteria and/or listed occupation are met and duration of exposure is confirmed (Belgium, Denmark, France, Germany, Hungary, Italy, Lithuania, Macedonia, Netherlands, Romania, Slovakia, Sweden, and Switzerland). LBPD due to vibrations can be also recognized as occupational in 14 countries. In 8 countries LBPD are not accepted as occupational unless they are caused by an injury at work. Specific criteria to evaluate occupational exposure of patients with LBPD were set in Belgium, Denmark, France, Germany, Lithuania, Macedonia, Netherlands, and Slovakia. In other countries, the evaluation is done at an individual basis.

Conclusions: In practice, the assessment of occupational overload and its contribution to the development of LBPD as well as its inclusion in the compensation system are important for several reasons. Firstly, it may be considered essentially preventable. Secondly, cases with a significant contribution of occupational aetiology may be viewed as occupational diseases for which compensation may be claimed, as it is the case in many European countries. Importantly, inclusion of LBPD in the list of occupational diseases or another system of compensation may be viewed as a preventive measure as it increases the visibility of this problem not only for the workers, but especially for the employers.

Key words: low-back pain diseases, heavy-weight lifting, overload, occupational disease, criteria, compensation 
Address for correspondence: A. Laštovková, Charles University, First Medical Faculty, Department of Occupational Medicine, Na Bojišti 1, 12000 Prague, Czech Republic. E-mail: azava@email.cz

\section{INTRODUCTION}

Regular physical activity including sport is considered a positive factor contributing to a higher quality of life and reduction of obesity $(1,2)$. On the other hand, excessive physical workload still occurring in many occupations leads to frequent musculoskeletal disorders and neurological damage of the upper extremities (3, 4 ). The spine belongs to the most frequently overloaded parts of the body during different work operations. Lifetime prevalence of low-back pain diseases (LBPD) across the general population worldwide is very high, reaching $84 \%$ (5), which makes the determination of the occupational cause of LBPD very difficult. According to data from the Institute of Health Information and Statistics of the Czech Republic, musculoskeletal diseases (MSD) accounted for almost $20 \%$ of work disability cases in the year 2012 and represented the second most frequent cause after respiratory diseases. The mean duration of sick leave due to this diagnosis was 67.7 days. Among all MSD, dorsopathies, particularly of the lumbar part of the back, were most common. Craftsmen, serviceman and non-qualified workers were most often affected (6).

This situation is quite similar across Europe. In Germany, with a population of almost 82 million, MSD caused $23.3 \%$ of the sick leaves in 2010 with approximately 26,000 new disability pensions which resulted in a loss of production corresponding to $€ 9.1$ billion (7). It has been proven that factors such as lifestyle, social factors, residence location, and type of workload have an impact on health condition and prevalence of diseases, including $\operatorname{LBPD}(8,9)$.

Employees working as nurses, hospital attendance, craftsmen, fishermen, warehousemen, etc. are daily exposed to heavy-weight lifting usually in unfavourable work postures which may cause damage to the vertebral column. Harmful effects of physical overload or whole-body vibrations affect mainly the lumbar intervertebral discs, which are getting narrower. Secondary changes such as subchondral sclerosis and osteophytes appear later and overload of the intervertebral joints results in early arthrosis. In this vulnerable area herniation of the disc and radicular syndrome are frequent (10).

According to an EU Report from 2013 (11), 22 out of 29 countries, covered by the study, consider risk prevention as their priority. Specifically, in 16 countries a priority in the prevention of the diseases is given to musculoskeletal disorders. These are Belgium, Cyprus, Denmark, Estonia, Finland, France, Germany, Hungary, Iceland, Italy, Netherlands, Norway, Poland, Portugal, Spain, and the United Kingdom. Musculoskeletal diseases have become a research priority in 10 of those countries, namely Belgium, Denmark, Estonia, Finland, France, Germany, Netherlands, Norway, Poland, and Sweden.

To be recognized as an occupational disease, a condition or sickness is required to meet certain medical and legal criteria. The problem of definition of such criteria is directly related to the reliability of a medical expert's assessment and conclusions (12). Certain discrepancies between the legal and medical concepts of occupational disease are practically inevitable, which brings another problem of admissibility of medical criteria, i.e. its compliance with the legal requirements (13).
The main reason why setting the criteria and compensation of LBPD as occupational diseases is rather difficult is the fact that the prevalence of LBPD in the general population is high. Lötters et al. (14) performed a meta-analysis of 40 studies and compared the prevalence of non-specific low-back pain in an unexposed population versus a population exposed to several risk factors. They found that the unexposed population under 35 years had $22 \%$ probability of having LBPD, people between 35 and 45 years $30 \%$ and people over 45 years $34 \%$. The pooled odds ratio (OR) was 1.51 (95\% CI 1.31-1.74) for manual materials handling, 1.68 (95\% CI 1.41-2.01) for frequent bending or twisting, 1.39 (95\% CI 1.24-1.55) for whole-body vibrations, and 1.30 (95\% CI 1.17-1.45) for job dissatisfaction. For high exposure to manual materials handling, frequent bending or twisting, and whole-body vibrations, the pooled OR was $1.92,1.93$, and 1.63 , respectively (14).

Also according to Kuiper et al. (15) who set the criteria for determining work-relatedness of low back pain in the Netherlands on the basis of a mathematical model, the main significant physical risk factors are: manual materials handling, frequent bending or twisting of the trunk, high physical workload and whole-body vibrations. The physical risk factors with a pooled OR being statistically significant in the meta-analysis $(p<0.05)$ were included in the model. These included manual materials handling (OR 1.51; 95\% CI 1.31-1.74), frequent bending or twisting of the trunk (OR 1.68; 95\% CI 1.41-2.01) and wholebody vibrations (OR 1.39; 95\% CI 1.24-1.55). The pooled OR of the psychosocial risk factor "job dissatisfaction" was also significant (OR 1.39; $95 \%$ CI 1.17-1.45). However, on the basis of the international consensus it was decided not to include this factor in the model because it is difficult to separate job dissatisfaction from the individual component. The model is presented as a score table from which the probability of work-relatedness can be read off for a given exposure. The total exposure score is counted by adding points for high/low or no exposure to the crucial risk factors after adjustment to the age (Table 1). The interval of the score ranges between $0-22$ points and indicates the percentages of work-relatedness for the appropriate age group. The occupational origin of the low-back pain of the patient is prevailing if the $50 \%$ limit is exceeded. The minimum score to exceed this limit increases with the age of the subject. Eleven exposure points are needed for the patients in the age group $<35$ years, 13 points are necessary for the age group in the range of 35-45 years, and 15 exposure points must be reached in the subjects $>45$ years to consider their exposure sufficient to cause occupational low-back pain (14).

The German Mainz-Dortmund Dose Model, introduced in 1999, was based on counting the biomechanical forces on the lumbosacral area during a specific workload. This model was supported by the German Spine Study EPILIFT $(16,17)$ performed in 2002-2007. This study included 915 occupationally exposed subjects versus 901 controls from four German regions. Compressive forces on the disc during the lifetime were calculated for each specific job with object handling and load-intensive postures via biomechanical model calculations applying the three- 
Table 1. Calculation of exposure score to evaluate the work-relatedness of non-specific low-back pain based on a flowchart by Lötters et al. (14)

\begin{tabular}{|l|c|c|c|}
\hline \multirow{2}{*}{ Risk factors } & \multicolumn{2}{|c|}{ Score if risk factor present } & \multirow{2}{*}{ Partial exposure score } \\
\cline { 2 - 4 } & Low exposure & High exposure & \\
\hline Lifting or manual materials handling & +4 & +7 & $\ldots .$. \\
\hline Frequent bending or twisting of the trunk & +5 & +7 & $\ldots .$. \\
\hline Whole-body vibration & +3 & +5 & $\ldots$. \\
\hline Low job satisfaction & +3 & - & $\ldots$. \\
\hline Total exposure score (0-22) & & & $\ldots$. \\
\hline
\end{tabular}

High exposure score: manual material handling $>15 \mathrm{~kg}$ for $10 \%$ of the worktime; bent and/or twisted trunk $>40^{\circ}$ for $>1 / 2$ hour per working day; whole body-vibration $>1 \mathrm{~m} / \mathrm{s}^{2}$ per working day for $\geq 5$ years.

Low exposure score: manual material handling $>5 \mathrm{~kg}>2 \mathrm{x}$ per minute for total of $>2$ hours per working day; or objects $>25 \mathrm{~kg}>1 \mathrm{x}$ per day bent and/or twisted trunk $>20^{\circ}$ for $>2$ hours per working day; whole body-vibration $>0.5 \mathrm{~m} / \mathrm{s}^{2}$ per working day.

dimensional dynamic simulation tool "The Dortmunder". For this analysis, all manual handling of objects of about $5 \mathrm{~kg}$ or more and postures with trunk inclination of $20^{\circ}$ or more were included in the calculation of the cumulative lumbar load. OR was found higher for exposed persons than for non-exposed subjects for each of the four exposed groups (disc herniation/disc narrowing among males/females), ranging between OR 1.3 and OR 3.9 in the respective dose category. According to this study the cumulative lumbar load was positively associated with both disc hernia and disc narrowing in women and men. The diagnosis of lumbar disc herniation had to be confirmed by computerized tomography (CT) or by magnetic resonance imaging (MRI); the diagnosis of lumbar disc narrowing was based primarily on the radiograph. The exposure criteria for recognizing LBPD as occupational are presented in Table 2.

In the Czech Republic, the list of occupational diseases is updated every two years. However, LBPD caused by overload and/or whole-body vibrations were not included in the last update of the list, valid from 1 January 2015. In a project funded by the Czech Ministry of Health both clinical and hygienic criteria are suggested for this new item in a chapter called "Diseases Caused by Physical Factors".

To get the data from other European countries, this study describing their approach to recognition of LBPD as occupational has been performed across Europe.

Table 2. Exposure criteria for $\angle B P D$ acknowledgement in Germany (Berufskrankheit Nr. 2108)

\begin{tabular}{|l|c|c|}
\hline Task & Female & Male \\
\hline Bi-manual lifting & $10 \mathrm{~kg}$ & $15 \mathrm{~kg}$ \\
\hline Lifting with one hand & $5 \mathrm{~kg}$ & $10 \mathrm{~kg}$ \\
\hline Bi-manual load transfer (ideal posture) & $20 \mathrm{~kg}$ & $30 \mathrm{~kg}$ \\
\hline Load transfer with one hand (ideal posture) & $5 \mathrm{~kg}$ & $10 \mathrm{~kg}$ \\
\hline $\begin{array}{l}\text { Bi-manual carrying besides the body, on the } \\
\text { shoulders or back }\end{array}$ & $20 \mathrm{~kg}$ & $30 \mathrm{~kg}$ \\
\hline Onesided carrying & $15 \mathrm{~kg}$ & $25 \mathrm{~kg}$ \\
\hline Pulling & $250 \mathrm{~N}$ & $350 \mathrm{~N}$ \\
\hline Pushing & $300 \mathrm{~N}$ & $450 \mathrm{~N}$ \\
\hline
\end{tabular}

Pre-selecting criteria before applying the Mainz-Dortmund Dose Model

\section{MATERIALS AND METHODS}

A questionnaire focused on LBPD was designed to be filled in by specialists in occupational diseases in European countries. The questions included use of list of occupational diseases in their country and if specific diagnoses were included, criteria for recognition of LBPD as occupational diseases, and the possibility of compensation for patients due to such diseases.

Specialists in occupational medicine from 25 European countries, members of the consortium MODERNET (Network for development of new techniques for discovering trends in occupational and work-related diseases and tracing new and emerging risks) were addressed, of whom 22 participated in our study, besides the Czech Republic. The total number was then 23 participants. Representatives of each country had to fill in the questionnaire focused on the possibility to recognize LBPD as occupational diseases in their country.

A literature search and electronic consultations with occupational specialists from selected countries were performed.

\section{RESULTS}

Of the 23 European countries participating in the study, 13 countries recognize LBPD due to physical overload as an occupational disease, while Bosnia and Herzegovina, Croatia, Czech Republic, Finland, Great Britain, Ireland, Norway, Poland, Portugal, and Spain do not acknowledge LBPD due to overload of the spine (Table 3 ).

Three countries, Hungary, Sweden and the Netherlands do not use a list of occupational diseases. However, any disease can be recognized as occupational in those countries if the causality is sufficiently proven. In addition, 14 countries acknowledge LBPD due to whole-body vibrations (Belgium, Croatia, Denmark, France, Germany, Hungary, Italy, Lithuania, Netherlands, Italy, Portugal, Slovakia, Sweden, and Switzerland). All 23 countries accept occupational injuries of the spine. Patients with occupational diseases may be granted financial benefits in all countries studied, except for the Netherlands and Macedonia.

Nevertheless, criteria for the recognition of LBPD as occupational differ from country to country (Table 3). Most of the countries use an individual evaluation of the patients' disorder and related work overload assessed by medical, hygienic, and ergonomics specialists, but no guidelines are provided. The specialists 
take a detailed occupational history, medical history, consider the age of the patient, length of the chronic or recurrent complaints, diagnosis, functional impairments based on the neurological/ orthopaedic examination, consistency of clinical and radiological findings (CT or MRI), consider competing factors, e.g. scoliosis, injuries, Bechterew's, etc. Some countries use computer models (Germany), while other use mathematical models (the Netherlands, Slovakia), aimed to individually assess the relationship between occupational workload and LBPD and its causality for an affected worker. Presented below are the systems in some of the countries that participated in the study.

In 1992, Germany established one of the first systems to evaluate LBPD due to physical overload with the possibility of workers' compensation after reunion of the Eastern and Western parts of Germany (18). In 1993, occupational disease no. 2108 was introduced ("disc-related diseases of the lumbar spine caused by the lifting or carrying heavy loads over many years or by performance of work in an extremely bent posture over many years which have forced the person to discontinue all activities that caused or could cause the development, worsening or recurrence of the disease"). If pre-selective physical exposure limits are met (Table 2) then physical exposure is evaluated by the Mainz-Dortmund Dose Model using the peak compressive force (expressed in N) on the lumbosacral disc by biomechanical models in certain exemplary occupations taking into consideration duration and frequency of the action. Cumulative lumbar load is measured by summing up the load in one shift multiplied by number of shifts during lifetime. If the workload exceeds the limits set by the model, a closer investigation of the worksite and individual tests are performed.

The Belgian system which was enacted in 2004 and in which LBPD can be recognized as occupational diseases both due to overload and whole-body vibrations was inspired by the German model. This update was based on studies by Hartung et al. (19) and Jäger et al. (20) proving a statistically significant association of radicular syndrome due to a disc herniation or early degenerative changes at the vertebral column before 40 years of age with spine overload and/or whole-body vibrations. On the other hand, simple spondylarthrosis or back pain without radicular syndrome was not found to be statistically significant enough to serve as a proof of work-relatedness. The criteria for recognition include the specific diagnosis (Table 2), calculation of compressive forces on the lumbar vertebral column according to the Mainz-Dortmund Dose Model, CT or MRI scans and electromyography.

In Macedonia, LBPD can be acknowledged only as a result of excessive effort of muscles and tendons and their attachments. Besides criteria mentioned in Table 3 there have to be present clinical signs of inflammation, reduction of movements, evidence based progression of the disorder as well as the absence of disorder before the employment. There are no additional specification of the job and recommended clinical investigation.

In the Netherlands, a rather different system to evaluate causality has been used since 2005 for non-specific low-back pain based on results of Lötters et al. (14). This probability mathematical model is designed as a three-step plan including at first setting the right diagnosis and excluding other diseases such as ankylosing spondylitis, malignancies, osteoporosis and other primary diseases that also might have caused the low-back symptoms (15).

If work-relatedness is suspected, the second step is to evaluate the work-relatedness of the risk factors: exposure to lifting and carrying, bending of the trunk and whole-body vibration, as shown in Table 1. The last step consists of summing up points from exposure to each of the three risk factors to get the total score of the probability of work-relatedness, as shown in Table 1. The decision model is based on the so called "a priori probability" of LBPD in the population, which was derived from meta-analysis of epidemiological studies on LBPD (14).

If the score exceeds $50 \%$, then the work-relatedness is seen sufficient for an occupational disease. Additionally, work-relatedness can be accepted if the probability is equal to or less than $50 \%$, if the NIOSH Lifting Index exceeds 2 (values $>1$ indicate an increased risk) $(21,22)$ or if the exposure to whole-body vibrations exceeds the European guideline limit $(23,24)$. The purpose of this model was to support occupational physicians in determining whether non-specific low back pain can be classified as an occupational disease (23-26). Its advantage is that it can be applied individually and is adjusted on a worker's own risk factors mentioned previously and takes into account the age of the person. Moreover, the risk of three separate risk factors can be summarized.

Recently in the Netherlands, also a criteria document was developed to assess whether lumbar herniated disc disease (lumbosacral radicular syndrome) can be classified as an occupational disease. The document is based on a systematic review on workrelated risk factors. The work-relatedness of lumbar herniated disc disease can be confirmed as an occupational disease if the exposure is characterized by more than 10 years of physically demanding work, such as daily lifting and carrying of loads of at least $5 \mathrm{~kg}$ on average 2 hours or 25 times per day, including bending of the trunk more than $20^{\circ}$ for at least one hour a day. The assumption that driving a vehicle by itself is a risk factor for lumbar herniated disc disease was not supported by this review.

Nevertheless, even if these diagnoses are reported as occupational diseases by an occupational physician there is no financial compensation for these occupational diseases in the Netherlands unless the conflict goes to court which gives a positive verdict.

In Slovakia, it is possible to recognize LBPD as occupational disease since 2004 when an open item "other harms to health caused by work" was incorporated into the list of occupational diseases.

Occupational LBPD due to overload include intervertebral disc-related diseases of the lumbar spine after many years of carrying or lifting heavy loads, in occupations with extreme postures of full flexion, bending and twisting of the trunk. Low-back pain should last more than 3 months and should lead to the cessation of all related work activities. Pathological changes found in the thoracic or cervical spine or severe arthroses in great joints do not support the occupational origin and the recognition of the LBPD as an occupational disease and compensation (Table 3 ).

In addition, the occupational overload/workplace risk factor must be confirmed by an occupational hygienist in every patient. The evaluation of occupational causality is based on Lötters et al. (14).

In Switzerland, the aetiologic contribution due to occupation is estimated individually by physicians specialized on occupational medicine. For overdose induced LBPD, the causality of the occupational workload has to be $75 \%$ or more, if the diagnosis has been confirmed by imaging methods. For vibrations induced damages, the aetiologic contribution of the occupation of $50 \%$ or more is sufficient.

France uses item no. 98 of the French list of occupational diseases related to LBPD - heavy-weight lifting, which was 


\begin{tabular}{|c|c|c|c|c|c|c|c|c|c|c|c|c|c|c|c|}
\hline 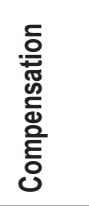 & $\stackrel{\infty}{\rightleftharpoons}$ & $\stackrel{\mathscr{\infty}}{>}$ & $\stackrel{\mathscr{\infty}}{=}$ & $\stackrel{\mathscr{\infty}}{>}$ & $\stackrel{\infty}{=}$ & $\stackrel{\mathscr{\infty}}{\rightleftharpoons}$ & $\stackrel{\mathscr{ٌ}}{\rightleftharpoons}$ & $\stackrel{\infty}{=}$ & $\stackrel{\mathscr{\infty}}{=}$ & $\stackrel{\mathscr{\infty}}{>}$ & 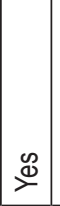 & $\stackrel{\infty}{\stackrel{\infty}{\infty}}$ & $\stackrel{\mathscr{J}}{\rightleftharpoons}$ & 은 & 2 \\
\hline 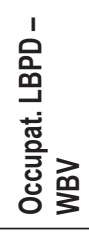 & $\stackrel{\infty}{\infty}$ & 2 & $\stackrel{\mathscr{\infty}}{=}$ & 2 & $\stackrel{\infty}{\check{\infty}}$ & 2 & $\stackrel{\mathscr{J}}{=}$ & $\stackrel{\infty}{\rightleftharpoons}$ & 운 & $\stackrel{\mathscr{\infty}}{\rightleftharpoons}$ & 2 & $\stackrel{\infty}{\rightleftharpoons}$ & 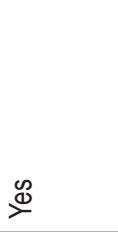 & 을 & $\stackrel{\mathscr{\infty}}{\rightleftharpoons}$ \\
\hline 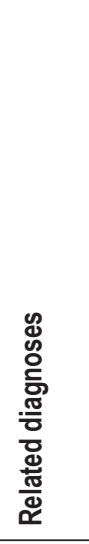 & 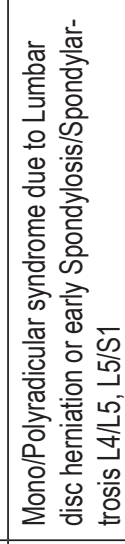 & $\Sigma$ & $\bar{z}$ & $\Sigma$ & 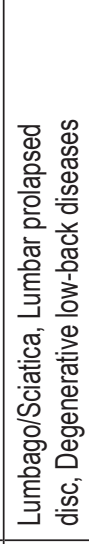 & & 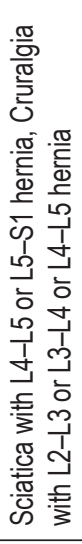 & 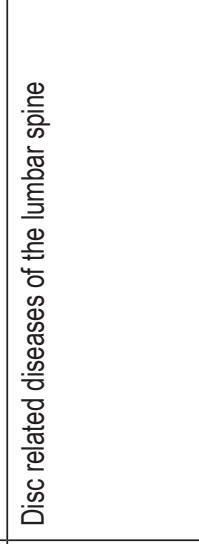 & $\Sigma$ & 产 & 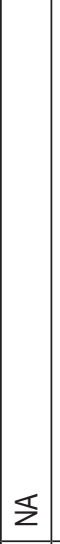 & 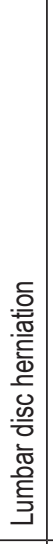 & 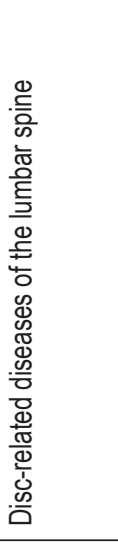 & 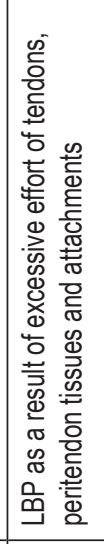 & 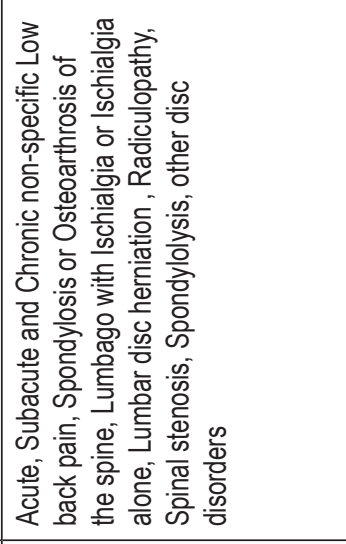 \\
\hline 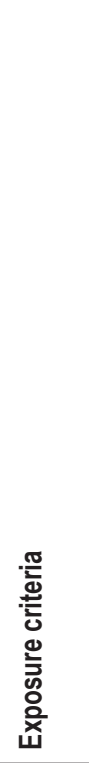 & 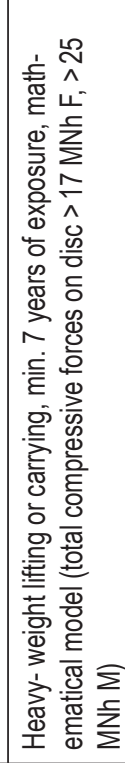 & 은 & 운 & 2 & 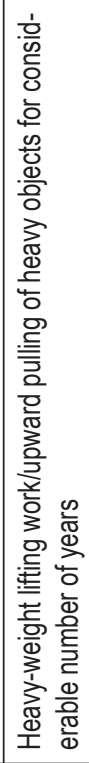 & 2 & 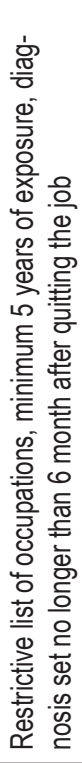 & 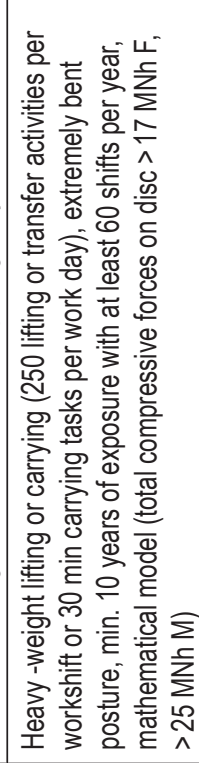 & 울 & 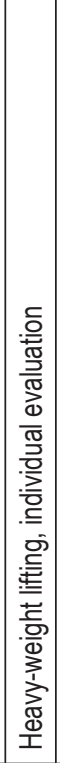 & \begin{tabular}{|l}
2 \\
2
\end{tabular} & 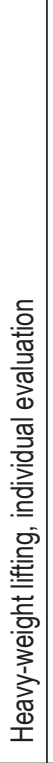 & 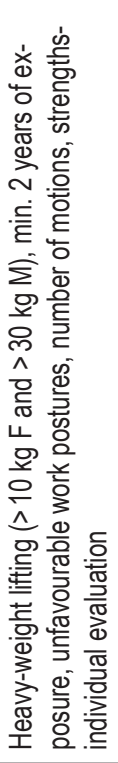 & 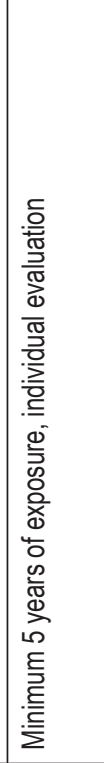 & 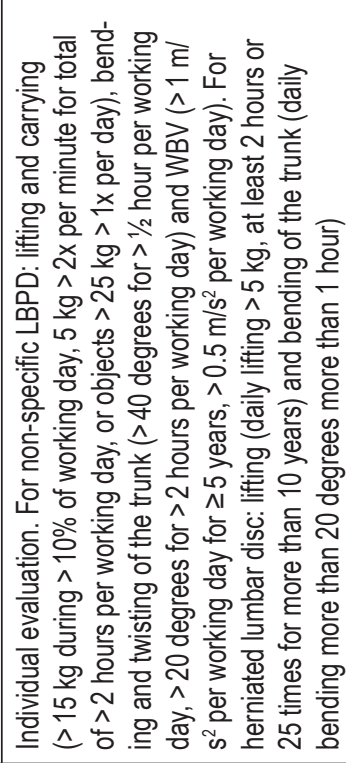 \\
\hline 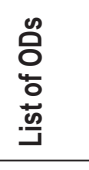 & $\stackrel{\mathscr{J}}{\rightleftharpoons}$ & $\stackrel{\mathscr{J}}{\rightleftharpoons}$ & $\stackrel{\mathscr{\infty}}{\rightleftharpoons}$ & $\stackrel{\mathscr{\infty}}{=}$ & $\stackrel{\infty}{>}$ & 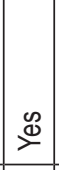 & $\stackrel{\mathscr{\infty}}{=}$ & $\stackrel{\mathscr{D}}{\rightleftharpoons}$ & $\stackrel{\infty}{\rightleftharpoons}$ & 2 & $\stackrel{\mathscr{\infty}}{\sim}$ & $\stackrel{\mathscr{\infty}}{\check{\infty}}$ & 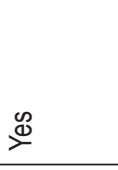 & $\stackrel{\infty}{\infty}$ & z \\
\hline 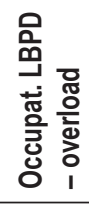 & $\underset{>}{\infty}$ & 을 & 2 & 2 & $\stackrel{\infty}{\infty}$ & 2 & 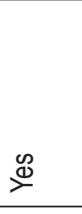 & $\stackrel{\mathscr{E}}{>}$ & 2 & $\stackrel{\mathscr{S}}{2}$ & 2 & $\stackrel{\infty}{2}$ & $\stackrel{\mathscr{J}}{\stackrel{0}{2}}$ & $\stackrel{\mathscr{\infty}}{\rightleftharpoons}$ & $\stackrel{\mathscr{H}}{\rightleftharpoons}$ \\
\hline $\begin{array}{l}\text { Dì } \\
\text { 总 } \\
\text { d }\end{array}$ & 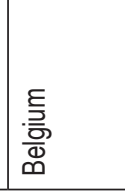 & 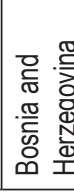 & & 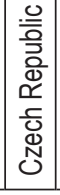 & 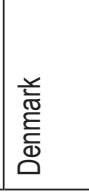 & 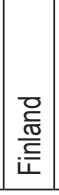 & 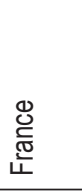 & 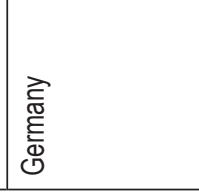 & 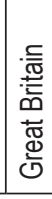 & 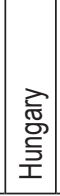 & 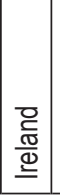 & 츨 & 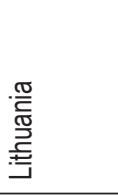 & 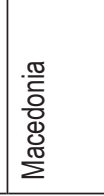 & 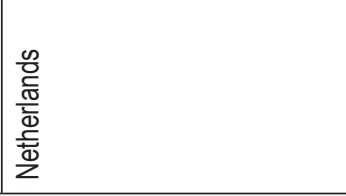 \\
\hline
\end{tabular}




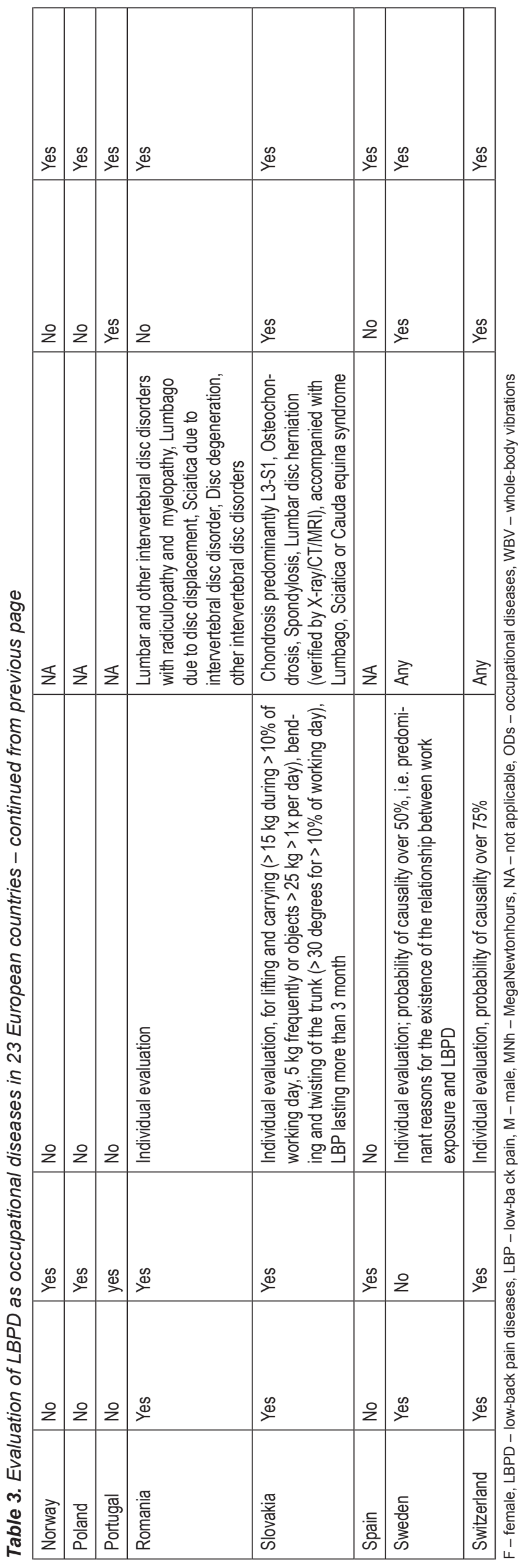

introduced in 1999 (27). To benefit from work-relatedness presumption, and allow "automatically" the recognition of LBPD as occupational in a patient, he/she has to meet three following conditions: to present with sciatica/radiculalgia and corresponding disc hernia (see Table 3); to have been exposed to heavy-weight lifting for minimum 5 years, and the interval from the last exposure to the diagnosis must not exceed 6 months; and to have worked in the following occupation/branch of industry: goods or merchandise transportation (by road, see, railway or air), construction, mining and quarrying, furniture removal, collection of household garbage or industrial waste, slaughterhouses and rendering companies, loading and unloading during manufacture or delivery, storage and distribution of goods from industry, agriculture, forestry, and food-industry, medical and paramedical activity including handling patients, medical transportation, and funeral work. The primarily concerned jobs are: handlers, labourers, shippers, warehousemen, porters, dustmen, renderers, furniture removers, caregivers in a hospital or at home, and undertakers. Over the last 10 years (2004-2013), the mean annual number of chronic LBPD, attributed to heavy-weight lifting and compensated as occupational diseases for salaried workers (outside the agriculture sector; total number of employees covered over 18.6 million) was 2,688 (standard deviation: 307) (28).

A similar system exists for the employees from the agriculture sector (covering about 1.2 million workers), and only the third condition differs. Indeed, the manual handling of heavy loads should be carried out in the agriculture and forestry, sawmills, shellfish and fish companies, agricultural contractors, landscaping companies, rural craft industries, slaughterhouses and rendering plants, loading and unloading during manufacture in the delivery, storage and distribution of the agricultural, food, forest, and industrial products.

Besides that, in several countries, another possibility to claim the recognition of LBPD due to heavy-weight lifting exists. In France, for example, it may be used for those patients with LBPD who do not completely meet the criteria regarding duration of exposure, list of activity, or the date of last exposure. In this case, there is usually no presumption of causality, and the file is studied by a committee of specialists to evaluate the link with the occupation. In France, LBPD and heavy-weight lifting accounted for $12 \%$ of this kind of claims, i.e. about 2,250 from a total of 18,809 cases in 2013 . Only some of them have been compensated.

\section{DISCUSSION}

There is no doubt that work overload is a contributing factor to LBPD. However, because they belong to very prevalent diagnoses in the working population, the reliable verification of the overload is crucial. Several countries may serve as an example of good practice. However, the evaluation of working conditions is demanding and time consuming.

New occupational risks are expected to result from new technologies, changing work organisation, the ageing work force, globalisation with an increasing work pressure and information supply. It is important to identify and tackle these new risks and working conditions at an early stage (11). It has been proven that the physical overload may cause or worsen LBPD (29) and along with a great economic burden, these disorders constitute a 
global social problem. A study within the EU calculates the cost of work-related ill health at a minimum of $€ 145$ billion, the cost to society has been estimated at $2-4 \%$ of the gross national product in different European countries (11).

To effectively trace new and emerging diseases the multinational consortium MODERNET has been established. The monitoring system is based on the reporting done by physicians, i.e. a form of a "sentinel" system. Such a network will support the work of occupational and safety specialists and physicians as it will enable a rapid exchange of information and examples of appropriate preventive actions (11). The MODERNET network has been used to collect data concerning potentially work-related LBPD in European countries and new diseases may be consulted with the MODERNET specialists in the Occupational Diseases Sentinel Clinical Watch System (30).

Technical prevention and good organization of the work is the basis for reduction of LBPD (11). However, inclusion of LBPD in the list of occupational diseases or other systems of compensation may be viewed as a preventive measure as it increases the visibility of this problem not only for the workers, but especially for the employers.

As can be seen from Table 3, there is no consensus concerning the diagnoses accepted; some countries do not exclude any diagnosis related to the vertebrogenic algic syndrome, others request lumbar disc herniation and/or protrusion and severe disc narrowing. In other countries, spondylosis with certain disc lowering shown on a scan, or spondylarthrosis on the one side, or sensitive and/or motor radicular syndrome or local lumbar syndrome on the other side are required.

In addition, further difficulties occur in the diagnosis as, even the most modern imaging methods including MRI do not correlate with the severity of subjective symptoms in most patients and their prognosis $(10,31)$. MRI is very sensitive and depicts incipient symptoms of degenerative spine impairment. Nevertheless, there is only a weak relation with the magnitude of clinical impairment. In many cases disc herniation can be seen on MRI in an asymptomatic patient. On the other hand, only minor MRI findings can be frequently seen in patients with a distinct algic syndrome. Probably, a disturbance in spine function will be the significant factor in this case resulting in blockage or hypermobility of a certain spine segment (32). MRI findings only poorly correlate with a clinical disability and they only minimally predict back pain episodes; there is no association with future disability. This is in contrast to psychosocial determinants which yield a strong correlation (33).

Therefore, several European countries do not include this diagnosis in their lists of occupational diseases and do not recognize LBPD as occupational diseases. This study documents a different approach to the problem of work overload and consideration of LBPD as occupational diseases in participating countries of this survey. Each country uses its own criteria for recognition of LBPD as occupational, according to their history and progress achieved in this field.

In the Czech Republic, criteria for recognition in individual patients are being created, based on data collected from the EU countries as well as on an occupational history and neurological examination and MRI in Czech workers exposed to overload of the spine. Their working conditions are being investigated by both standard physiology methods and Tecnomatix Jack software (lower back pain analysis, static strength prediction and NIOSH lifting), focused on the load to the lumbar spine during occupational activities of the worker in comparison with NIOSH limits for disc L4/L5 compression $(3,400 \mathrm{~N}$ and 6,400 N). The compression during performance of occupational task has been computed for different anthropometric parameters of workers and the method will be adjusted to evaluate different tasks of the whole shift and finally validated in a study of 50 workers with clinically confirmed LBPD. New criteria are intended for the inclusion of LBPD in the next update of the Czech list of occupational diseases.

\section{CONCLUSIONS}

Although LBPD are very common diseases of multifactorial aetiology, epidemiological studies have shown a statistically significant association with certain types of occupational burden. This important public and economical issue has been solved in different ways across European countries. Diagnostic criteria differ substantially with respect to both verification of the workload and range of diagnoses of diseases accepted.

The study confirms the uncertainties in the evaluation. However, the well elaborated methods from several European countries may be used for comparison with the currently developed method for individual occupational, neurological and radiological examinations of the Czech patients and their workload using Tecnomatix Jack software.

\section{Conflict of Interests}

None declared

\section{Acknowledgement}

This project was supported by the Czech Grant Agency (IGA MZ ČR NT14471)

\section{REFERENCES}

1. Jakab Z, Tsouros AD. Health 2020 - achieving health and development in today's Europe. Cent Eur J Public Health. 2014 Jun;22(2):133-8.

2. Kim JH, So WY. Association between overweight/obesity and academic performance in South Korean adolescents. Cent Eur J Public Health. 2013 Dec;21(4):179-83.

3. Fenclová Z, Urban P, Pelclová D, Navrátil T. Neurological occupational diseases in the Czech Republic in 1994-2009. Cesk Slov Neurol Neurochir. 2012;75(1):70-4. (In Czech.)

4. Fenclová Z, Urban P, Pelclová D, Voříšková M, Havlová D. Occupational diseases reported in the Czech Republic in 2012. Prakt Lek. 2013;93(3):93-9. (In Czech.)

5. van Dieën JH, Kuijer PP, BurdorfA, Marras WS, Adams MA. Non-specific low back pain. Lancet. 2012 May 19;379(9829):1874; author reply 1874-5.

6. Institute of Health Information and Statistics of the Czech Republic. Terminated cases of incapacity for work for disease or injury 2012 [Internet]. Prague: Institute of Health Information and Statistics of the Czech Republic; 2013 [cited 2015 Sep 16]. Available from: http://www. uzis.cz/publikace/ukoncene-pripady-pracovni-neschopnosti-pro-nemocuraz-2012. (In Czech.)

7. Ellegast R. Lumbar discal herniation as occupational disease in Germany [Internet]. Sankt Augustin: IFA - Institute for Occupational Safety and Health of the German Social Accident Insurance; 2010 [cited 2014 Nov 14]. Available from: http://www.epmresearch.org/userfiles/files/R\%20 Ellegast\%20-\%20IFA.pdf.

8. Sofková T, Přidalová M, Mitáš J, Pelclová J. The level of neighborhood walkability in a place of residence and its effect on body composition in obese and overweight women. Cent Eur J Public Health. 2013 Dec;21(4):184-9. 
9. Babinská I, Madarasová Gecková A, Jarčuška P, Pella D, Mareková M, Štefková G, et al.; HepaMeta Team. Does the population living in Roma settlements differ in physical activity, smoking and alcohol consumption from the majority population in Slovakia? Cent Eur J Public Health. 2014 Mar;22 Suppl:S22-7.

10. Hart R, et al. Degenerative diseases of the spine. Prague: Galén; 2014. (In Czech.)

11. Report on the current situation in relation to occupational diseases' systems in EU Member States and EFTA/EEA countries, in particular relative to Commission Recommendation 2003/670/EC concerning the European Schedule of Occupational Diseases and gathering of data on relevant related aspects'March 2013 [Internet]. [cited 2014 Nov 14]. Available from: https://osha.europa.eu/data/links/commission-recommendationconcerning-the-european-schedule-of-occupational-diseases.

12. Zakharov $\mathrm{S}$. The problems of a medical expert's testimony reliability assessment in medical malpractice cases. Rom J Leg Med. 2011;19(4):291 4.

13. Zakharov S. The assessment of expert testimony relevance and admissibility in medical malpractice cases in the Czech Republic. Can American judicial practice help us? Rom J Leg Med. 2011;19(1):59-68.

14. Lötters F, Burdorf A, Kuiper J, Miedema H. Model for the workrelatedness of low-back pain. Scand J Work Environ Health. 2003 Dec;29(6):431-40.

15. Kuiper JI, Burdorf A, Frings-Dresen MH, Kuijer PP, Spreeuwers D, Lötters FJ, et al. Assessing the work-relatedness of nonspecific low-back pain. Scand J Work Environ Health. 2005 Jun;31(3):237-43.

16. Seidler A, Bergmann A, Jäger M, Ellegast R, Ditchen D, Elsner G, et al. Cumulative occupational lumbar load and lumbar disc disease - results of a German multi-center case-control study (EPILIFT). BMC Musculoskelet Disord. 2009 May 7;10:48. doi: 10.1186/1471-2474-10-48.

17. Schumann B, Bolm-Audorff U, Bergmann A, Ellegast R, Elsner G, Grifka J, et al. Lifestyle factors and lumbar disc disease: results of a German multi-center case-control study (EPILIFT). Arthritis Res Ther. 2010;12(5):R193. doi: 10.1186/ar3164.

18. Jäger M. Evaluating the link between disc herniation and manual materials handling. In: Lumbar discal herniation and work: What relationship?: International symposium; 2012 Mar 6; University of Milan.

19. Hartung E, Schäfer K, Jäger M, Luttmann A, Bolm-Audorff U, Kuhn S, et al. The Mainz Dortmund Dose Model (MDD) for assessing the load on the lumbar spine caused by lifting and carrying heavy objects or by work with the trunk fully inclined in suspicion of occupational disease no. 2108. Part 2: Suggestion for the assessment of work-related prerequisites in occupational disease evaluation. Arbeitsmed Sozialmed Umweltmed. 1999;34(3):112-22. (In German.)

20. Jäger M, Luttmann A, Bolm-Audorff U, Schäfer K, Hartung E, Kuhn S, et al. The Mainz Dortmund Dose Model (MDD) for assessing the load on the lumbar spine caused by lifting and carrying heavy objects or by work with the trunk fully inclined in suspicion of occupational disease no. 2108. Part 1: Retrospective load estimation for risky jobs. Arbeitsmed Sozialmed Umweltmed. 1999;34(3):101-11. (In German.)
21. Waters TR, Putz-Anderson V, Garg A, Fine LJ. Revised NIOSH equation for the design and evaluation of manual lifting tasks. Ergonomics. 1993 Jul;36(7):749-76.

22. Waters TR, Baron SL, Piacitelli LA, Anderson VP, Skov T, HaringSweeney M, et al. Evaluation of the revised NIOSH lifting equation. A cross-sectional epidemiologic study. Spine (Phila Pa 1976). 1999 Feb 15;24(4):386-94.

23. Miedema HS, van der Molen HF, Kuijer PP, Koes BW, Burdorf A. Incidence of low back pain related occupational diseases in the Netherlands. Eur J Pain. 2014 Jul;18(6):873-82.

24. Kuijer PP, van der Molen HF, Schop A, Moeijes F, Frings-Dresen MH, Hulshof CT. Annual incidence of non-specific low back pain as an occupational disease attributed to whole-body vibration according to the National Dutch Register 2005-2012. Ergonomics. 2015;58(7):1232-8.

25. van der Molen HF, Kuijer PP, Smits PB, Schop A, Moeijes F, Spreeuwers $\mathrm{D}$, et al. Annual incidence of occupational diseases in economic sectors in The Netherlands. Occup Environ Med. 2012 Jul;69(7):519-21.

26. EMUTOM: European module for undergraduate teaching of occupational medicine: teacher manual. EMUTOM; 2012.

27. French list of occupational diseases [Internet]. INRS [cited 2014 Nov 14]. Available from: http://www.inrs-mp.fr/mp/cgi-bin/mppage. $\mathrm{pl}$ ? state $=1 \&$ acc $=5 \& \mathrm{gs}=\& \mathrm{rgm}=2$. (In French.)

28. CNAM-TS. Direction des risques professionnelles. Directory of Occupational Risks. Rapport de Gestion 2013 [Internet]. Paris; 2013 [cited 2015 Sep 16]. Available from: http://www.risquesprofessionnels.ameli. fr/fileadmin/user upload/document PDF a telecharger/brochures/Rapport\%20de\%20Gestion\%202013.pdf. (In French.)

29. Burdorf A, Sorock G. Positive and negative evidence of risk factors for back disorders. Scand J Work Environ Health. 1997 Aug;23(4):243-56.

30. OccWatch [Internet]. OccWatch - a modernet tool; (C) 2015[cited 2015 Sep 16]. Available from: https://occwatch.anses.fr/.

31. Berg L, Hellum C, Gjertsen Ø, Neckelmann G, Johnsen LG, Storheim $\mathrm{K}$, et al.; Norwegian Spine Study Group. Do more MRI findings imply worse disability or more intense low back pain? A cross-sectional study of candidates for lumbar disc prosthesis. Skeletal Radiol. 2013 Nov;42(11):1593-602.

32. Seidl Z, Vaněčková M. Diagnostic radiology - neuroradiology. Praha: Grada; 2014. (In Czech.)

33. Carragee EJ, Alamin TF, Miller JL, Carragee JM. Discographic, MRI and psychosocial determinants of low back pain disability and remission: a prospective study in subjects with benign persistent back pain. Spine J. 2005 Jan-Feb;5(1):24-35. 